\title{
Psychodermatology: Past, Present and Future
}

\author{
Carmen Rodríguez-Cerdeira ${ }^{*}, 1$, José Telmo Pera-Grasa ${ }^{2}$, A, Molares ${ }^{3}$, Rafael Isa-Isa ${ }^{4}$, \\ Roberto Arenas-Guzmán ${ }^{5}$
}

\author{
${ }^{I}$ Dermatology Department, CHUVI and University of Vigo, Vigo, Spain \\ ${ }^{2}$ University of Vigo. Vigo. Spain \\ ${ }^{3}$ FIDI Xeral-Calde, Hospital Lucus Augusti, Lugo, Spain \\ ${ }^{4}$ Institute of Dermatology and Skin Surgery, Santo Domingo, Dominican Republic \\ ${ }^{5}$ Dermatology Department, Hospital Dr, Manuel Gea González, D.F., México
}

\begin{abstract}
A relationship between psychological factors and skin diseases has long been hypothesized. Psychodermatology addresses the interaction between the mind and the skin. Today, we know that it is essential to consider both biopsychosocial approaches and path physiological approaches to treatment, involving general practitioners, psychiatrists, dermatologists and psychologists. However, Psychodermatology is a relatively new discipline, and the body of literature addressing it is still scarce.

To obtain data, we consulted the archives of dermatological societies in Europe and America from the year of their founding until 2010. We also consulted other psychiatric and psychological societies and received responses from most of them.

Among the different stages in the historical evolution of Psychodermatology (the early, anecdotal phase; the methodological phase and the contemporary phase), it was only in the most recent phase that the European Society of Dermatology and Psychiatry was established. Other working groups and societies have emerged in several European countries: The German Working Group on Psychodermatology, French Society for Dermatology and Psychosomatics, Italian Society of Psychosomatic Dermatology, the Dutch Society of Psychosomatic Dermatology, the Spanish Society of Dermatology and Psychiatry etc.

More recently, a Psychodermatology two groups Psychodermatology were established first one within the Ibero Latin American College of Dermatology (CILAD) and the other one the Japanese Society of Psychodermatology (JSPD).

Summarize, this review details the historical evolution of the relationship between the skin and the mind. It also reveals the emergence of Psychodermatology as a discipline in its own right and describes the societies that have emerged worldwide as a result of collaboration between dermatologists and psychiatrists.
\end{abstract}

Keywords: Psychodermatology, European society of Dermatology and Psychiatry (ESDaP), Psychosomatic.

\section{INTRODUCTION}

The skin and central nervous system have common embryological origins; therefore, they also have common neuromodulators, peptides and biochemical systems of internal information. For this reason, the skin is an organ that is strongly reactive to emotion. Because the skin is the most accessible part of our body, it is not uncommon for many people to manifest aggressive impulses, anxiety, or selfdestructive behavior through the skin, provoking dermatological symptoms. On the other hand, people with skin diseases that compromise their self-image may feel depressed, ashamed or anxious as a result of their illness. Psychodermatology is the result of the merger of these two seemingly unrelated disciplines. Dermatology pertains to the

*Address correspondence to this author at the Dermatology Department, CHUVI and University of Vigo, Vigo, Spain; Tel: 00-34-600536114; Fax: 00-34-986-276416; E-mails: aristoteles_cerdeira@yahoo.es,

carmen.rodriguez.cerdeira@yahoo.es, crodcer@uvigo.es treatment of diseases of the skin, which are manifested externally. Psychology and Psychiatry pertain to the examination of mental processes, which are manifested internally.

Thus, these different approaches regarding the relationship between the psychic and the somatic are variations on a theme: the relationship between behavior, thought, and emotion and the biological body that sustains them.

An other important consideration is the link between inflammation and depression when depression is considered as a continuous dimensional variable rather than a categorical entity, as this allows one to take into consideration moderate and subclinical levels of depressed mood. For instance, a prospective study of 267, 85-year-old subjects with no psychiatric history revealed that elevated biomarkers of inflammation preceded the onset of depressed mood in an aged population with no psychiatric history; this 
Table 1. Inflammation and Depression

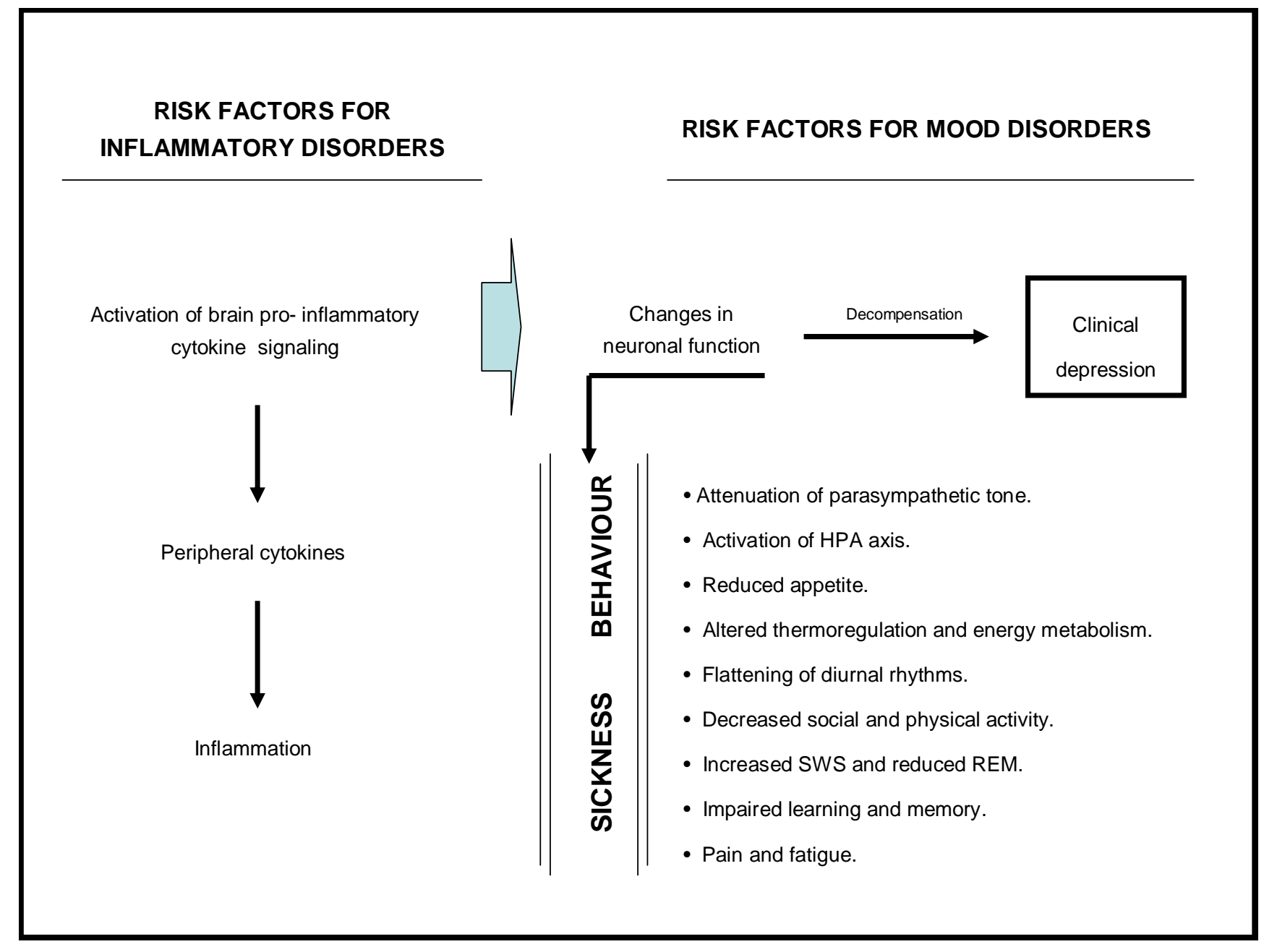

HPA: Hypothalamic-pituitary-adrenal, SWS: Slow-wave sleep, REM: Rapid eye movement.

must be taken into account in inflammatory conditions such as psoriasis (Table 1) [1].

Today, we understand that Psychodermatology is a merger between Dermatology and Psychiatry that deals with the study of the influence of psychosocial stress in the exacerbation or chronicity of skin illness [2, 3]. Psychodermatology also analyses existing psychiatric comorbidities in many dermatologic conditions and the role of adjuvant treatment, whether it be psychopharmacological, psychotherapeutic or social $[4,5]$. However, clarifying this definition has not been easy. It would not have been possible without the dedication and effort of many health professionals. From its beginnings, in which there was hardly any knowledge about Psychodermatology, this discipline has now turned into an exciting field of study and source of support for patients with skin problems. Dermatologists, psychiatrists and psychologists, should create instruments to measure the incidence of:

- $\quad$ Stress, depression and skin disease

- Hypothalamic alterations and disease

- Classical conditioning and disease
Skin diseases such as psoriasis can profoundly influence a patient's self-image, self-esteem, and sense of well-being. Psoriasis is a multifactorial inflammatory condition with a disease burden that extends beyond the physical symptoms experienced by patients. Psoriasis affects all aspects of quality of life, including physical, psychological, social, sexual, and occupational elements. Data suggest that social stigmatization, high stress levels, physical limitations, depression, employment problems and other psychosocial co-morbidities experienced by patients with psoriasis are not always proportional to, or predicted by, other measurements of disease severity such as body surface area involvement or plaque severity [6].

The relation between psychological factors and psychiatric disorders in patients with skin diseases was discussed by researchers at different stages of the evolutionary process of building the Psychodermatology as a science with its own identity. The one hand psychological factors (stress, negative emotions) can influence the generation and aggravation of skin disorders (urticaria, atopic dermatitis, vitiligo), on the other hand psychological disorders can result in some skin diseases (psoriasis, atopic 
dermatitis). In the majority of cases the quality of life is poorly estimated by patients with skin problems.

We can say that Psychodermatology has a long history but a short past, which means that we can trace its history from the earliest texts related to skin disease with mental states. However, we cannot refer to psychodermatology as a discipline until the mid-twentieth century. This discipline, despite its youth, has an interdisciplinary character and, indeed, was built and continues to be built through the efforts of many professionals from different areas of medicine [7].

The Bible includes several episodes in which a relationship is established between the mind and the skin. The book of Genesis states "He put a sign Lord Cain, lest anyone find him hurt you..." The mark of Cain is a sign that he is "protected" from any attack, and his skin serves as a defense mechanism $[4,8]$.

Shortly thereafter, in Exodus, in the sixth plague in which Yahweh punishes the Pharaoh, there is another instance in which the skin acts as a signifier: "... take a handful of ashes from the furnace and Moses throw it toward the sky, the sight of Pharaoh, so that converted into a fine powder on all the land of Egypt and occurs in all the land of Egypt both men and animals and tumors eruptive pustules... " In other words, the pustules and tumors are an anticipated consequence of the conduct of the Pharaoh [9].

Hippocrates related the effects of fear on the skin. He noted that when our heart beats faster and with unusual force, we begin to sweat. In 1850, Erasmus Wilson wrote a book titled "Diseases of the skin." In his chapter on cutaneous neuroses, he speaks of alopecia areata, hypopigmented lesions, itching and parasitism mania, now known as delusions of parasitosis. This book is considered by many to be the starting point of Psychosomatic Dermatology [10].

The relationship between emotions and skin disorders has been recognized for decades. In 1925, Joseph Klauder noted the importance of psychotherapy in the evolution of skin diseases [11].

However, we must stress that, even in early texts, dermatological diseases are present and often associated with psychological states, meaning that Psychodermatology is alluded to in the earliest writings despite the fact that the rigorous and scientific study of the subject did not begin until the mid-twentieth century $[12,13,14]$.

\section{EARLY STAGE/ANECDOTAL}

In this phase, simple relationships were sought between certain personality structures, states of emotional conflict (which were seen as causal phenomena), and something psychosomatic, which could be a dermatitis. It was assumed that this relationship was based on a detailed investigation of somatic, psychiatric and psychological behavior, the latter being based on a biographical history and results of psychological test batteries.

The pioneers in this phase were mainly psychiatrists trained in psychoanalysis or dermatologists who cooperated with psychiatrists.
At this stage, the concept of specificity arose: the hypothesis that a specific emotional conflict and a specific personality structure could be related to a certain psychosomatic disease or psychodermatitis [15].

Authors who are researching in this field thinking about the possibility of a linking with psychological stress to exacerbation of certain skin diseases. Both the clinical and the basic science evidence, however, can be hard to interpret in light of the difficulty of defining and quantifying psychological stress as well as the questions regarding the etiologic significance of neuroimmunological findings in skin diseases. Psychosomatic Dermatology is practiced in some manner by every dermatologist. In spite of this, there has been a virtual void in the literature from the middle 1950s until the present time.

\section{METHODOLOGICAL PHASE}

Around 1960, the field of psychology reacted to the anecdotal or initial phase. The material from which conclusions were drawn was considered insufficient and inadequate for statistical analysis and scientific assessment and prediction because it was often too selective and was not representative of the disease being studied. Control groups were few and the patient-doctor relationship was rarely noted.

Later, several other issues highlighting the defects of the anecdotal phase emerged in the literature: The motivation of the patient to receive treatment and the severity of emotional disturbance, regardless of the dermatitis, are essential. A specific set of symptoms of the disease, regardless of the dermatitis, can define the patient's behavior. The circadian rhythm of some metabolic processes, which have implications in the psychological and somatic behavior of the patient, have been sufficiently considered.

In this phase, the methodological approach takes into account the contributions of different disciplines to the scientific evaluation of psychodermatological phenomena. Therefore, conclusions that go beyond simple arguments, as occurred in the first anecdotal phase, can be drawn. At this stage, psychosomatic medicine and Psychodermatology were only an adjunct to psychoanalysis [16]. In that time clinicians trained in Dermatology and having submitted themselves to psychoanalysis have developed an original psychosomatic approach to skin disease at the Tarnier Hospital (Cochin-Port Royal University Hospital Center). Its main spring is detection and management of the patient's distress. They analyze the conditions under which it was possible to carry out this experiment and the implications of this approach which is directed at achieving a change in the way the department is run rather than adding one more specialized appendage to the outpatient care activity [17]

\section{INTEGRATIVE PHASE}

In this phase, the trend towards teamwork was more intense. The number of disciplines involved in increasing the awareness of psychological behavior was larger. The researcher and therapist were not only aware of the extent of the areas of contact with other biological sciences, but were also aware of the limits of their own contributions. Data pertaining to Psychodermatology requires not only thoroughness (such as psychoanalysis by trained people in 
the fifties), but also amplitude, so that increasing number of factors are taken into account [18].

The behavioral aspect of dermatitis goes beyond the individual. Dermatology has become aware of the fact that the pathology of skin diseases is part of the pathology of all humans.

It is obvious that in the formulation stage, the themes developed in the early stages remained significant, and the results of solid research contributed to knowledge. To provide the complete knowledge for monitoring patients with skin diseases, some factors, attitudes and variables were integrated, including some unmeasured factors resulting from the relationship with the patient (trying to change the patient's environment and goals) [19].

In this phase they considered that the most important theory for management of psycho-dermatological disorders requires evaluation of the skin manifestation and the social, familial and occupational issues underlying the problem. Once the disorder has been diagnosed, management requires a dual approach, addressing both dermatologic and psychological aspects. Even with self-induced skin problems, supportive dermatologic care is needed to avoid secondary complications, such as infection, and to ensure that the patient feel supported. Patients with psychodermatological disorders frequently resist referral to mental health professionals. Acceptance of psychiatric treatment or consultation may be enhanced through support from there family and friends [20].

\section{CONTEMPORARY PHASE}

In this phase they strongly believe that psychodermatological disorders can be broadly classified into some categories: psycho-physiological disorders, primary psychiatric disorders and secondary psychiatric disorders. The term "psycho-physiological disorder" refers to a skin disorder, such as eczema or psoriasis, that is worsened by emotional stress. "Primary psychiatric disorder" refers to a skin disorder such as trichotillomania, in which the primary problem is psychological; the skin manifestations are selfinduced. "Secondary psychiatric disorders" affect patients with significant psychological problems that have a profoundly negative impact on their self-esteem and body image. Depression, humiliation, frustration and social phobia may develop as a consequence of a disfiguring skin disorder. This was the first step to building a European society that brings together all stakeholders in a new subspecialty that was the Psychosomatic Dermatology.

May 31, 1987 can be set as the starting point for this stage. Michael Musalek, with the invaluable help of Peter Berner and John Cotterill, organized the first International Congress on Psychosomatic Dermatology in Vienna. This was conceived as the first opportunity to provide the exchange of scientific and clinical information. It was a successful event, both in terms of the quality of the presentations and the number of participants, about 200 people from 20 countries worldwide.

Michael Musalek invested a great deal of time and attention to administrative details, and the European Society of Dermatology and Psychiatry (ESDaP) was formally established by decree of Vereinsbehörde,
Sicherheitsdirektion für Wien, the Austrian Republic, on January 28, 1993. In 1989, John Cotterill held a second conference in Leeds. At the Third Congress, held in 1991 in Florence, Emiliano Panconesi held a meeting to formally discuss the creation of a stable association to organize periodic meetings to encourage contact between professionals and the exchange of scientific information (Table 2). The meeting was attended by Peter Berner (Vienna), Marc Bourgeois (Bordeaux), Sylvie Consoli (Paris), John Cotterill (Leeds), Francesc Grimalt (Barcelona), John de Korte (Amsterdam), Uwe Gielen (Giessen), Caroline Koblenzer \& Peter Koblenzer (Philadelphia), Michael Musalek (Vienna), Klaus Taube (Halle), Henriette Walter (Vienna) and Emiliano Panconesi (Florence) $[17,18]$. After an intense meeting, which focused on issues such as the frequency of the Congress and standardizing terminology, the European Society of Dermatology and Psychiatry was created. Differences in terminology in each country, such as Psychodermatology, Psychocutaneous Medicine, and Psychosomatic Dermatology were superseded.

\section{Table 2. International Conferences in Psychosomatic Dermatology}

\begin{tabular}{|c|c|c|}
\hline Chair & Year & Place \\
\hline \hline Michael Musalek & $1987\left(1^{\text {st }}\right)$ & Vienna (Austria) \\
\hline Jonh Cotterill & $1989\left(2^{\text {nd }}\right)$ & Leeds (UK) \\
\hline Emiliano Panconesi & $1991\left(3^{\text {rd }}\right)$ & Florence (Italy) \\
\hline Peter \& Caroline Koblenzer & $1992\left(4^{\text {th }}\right)$ & Philadelphia (UE) \\
\hline
\end{tabular}

The creators and executive committee members of the first society were

- John Cotterill (Leeds), Chairman

- Marc Bourgeois (Bordeaux), Vice President

- $\quad$ Michael Musalek (Vienna), Secretary General

- John de Korte (Utrecht), Treasurer

- $\quad$ Peter Berner (Vienna), Counsellor

- $\quad$ Sylvie Consoli (Paris), Counsellor

- $\quad$ Francesc Grimalt (Barcelona), Counsellor

- Uwe Gielen (Linden), Counsellor

- Emiliano Panconesi (Florence), Counsellor

- $\quad$ Taube Klau (Halle), Counsellor

- Henriette Walter (Vienna), Counsellor

A fourth international conference was held in 1992 in Philadelphia. Several European colleagues were invited to participate, but for various reasons, they could not attend. The conference was organized by Peter and Caroline Koblenzer. They tried to promote collaboration between the ESDaP and the Psychocutaneous Medical Association of North America (APMNA) (Table 2) [20-22].

The European Society for Dermatology and Psychiatry is a scientific society that was legally established in 1993 in Vienna under Austrian Law. It provides a forum for 
European physicians and psychologists working in the fields of Psychodermatology, Psychosomatic Dermatology, and Dermatopsychiatry to foster the exchange of information and ideas. The organization also fosters networking among professionals in the field to improve the quality of scientific research in the area and recruit new members with expertise in the field.

The ultimate aim of the society is to foster the improvement of patient care by putting into practice insights gained through research in Psychodermatology.

ESDaP further aims

- To stimulate interest in Psychodermatology, particularly among European dermatologists, psychiatrists, psychologists, and other professionals in this field and in related ones.

- $\quad$ To promote interdisciplinary research and education on subjects connected with Dermatology, Psychology and Psychiatry in order to improve both understanding of pathology as well as clinical management of psychocutaneous diseases.

- $\quad$ To organize symposia and international congresses on Dermatology, Psychology and Psychiatry, aiming to provide both medical professionals as well as the general public with updated information on developments in the field of Psychodermatology.

Subsequent meetings have all been specifically ESDaP congresses, the fifth congress was held in Bordeaux (France) in 1993 and was organized by psychiatrist Marc Bourgeois. The sixth was held in Amsterdam (The Netherlands) in 1995 and was organized by the psychologist John de Korte. The seventh was held in Halle (Germany) and organized by dermatologist Klaus Taube. In the next congress in Paris in 1999, dermatologist and psychiatrist Sylvie Consoli introduced the journal Dermatology \& Psychosomatics. There were also meetings in Holland and Germany. In 2001, Francesc Grimalt organized the ninth International Congress of ESDaP in Barcelona (Table 3).

Table 3. International Conferences of the European Society of Dermatology and Psychiatry (ESDaP)

\begin{tabular}{|c|c|c|}
\hline Chair & Year & Place \\
\hline \hline Marc Bourgeois & $1993\left(5^{\text {th }}\right)$ & Bordeaux (France) \\
\hline John de Korte & $1995\left(6^{\text {th }}\right)$ & Amsterdam (The Netherlands) \\
\hline Klaus Taube & $1997\left(7^{\text {th }}\right)$ & Halle (German) \\
\hline Sylvie Consoli & $1999\left(8^{\text {th }}\right)$ & Paris (France) \\
\hline Francesc Grimalt & $2001\left(9^{\text {th }}\right)$ & Barcelona (Spain) \\
\hline Françoise Poot & $2003\left(10^{\text {th }}\right)$ & Brussels (Belgium) \\
\hline Uwe Gieler & $2005\left(11^{\text {th }}\right)$ & Giessen (German) \\
\hline Francisco Tausk & $2007\left(12^{\text {th }}\right)$ & Wroclaw (Poland) \\
\hline Andrea Peserico & $2009\left(13^{\text {th }}\right)$ & Venice (Italy) \\
\hline $\begin{array}{c}\text { Lucia Tomás- } \\
\text { Aragonés }\end{array}$ & $2011\left(14^{\text {th }}\right)$ & Zaragoza (Spain) \\
\hline
\end{tabular}

The chair of the ESDaP was occupied successively by the teachers John Cotterill, Emiliano Panconesi, Sylvie Consoli, Françoise Poot, John de Korte and the President Elect is Michael Dennis Linder [20, 21].

Moreover, the ESDaP organizes lectures and symposia at every EADV congress and an international congress every other year. Currently, most countries in the European Union have their own national work group on Psychodermatology (French Society for Dermatology and Psychosomatics, Italian Society of Psychosomatic Dermatology, The German group on Psychodermatology, the Dutch Society of Psychosomatic Dermatology, etc.) [22-25].

The number of participants in those meetings has been fairly constant over the years. The quality of presentations has remained high, and participants demonstrate increasing interest in the topics presented. In addition, interest in the field has been growing in younger physicians and psychologists.

According to Emiliano Panconesi et al. [18] relations between Association for Psychocuataneous Medicine of North America (APMNA) and ESDaP have much greatly improved over the last five years as participation in meetings organized by both associations maintains frequent individual contacts between them [26, 27].

In Spain, it was not until 1995 when the first meeting of the Spanish Group of Dermatology and Psychiatry was held. It was attended by 138 attendees, including psychologists, psychiatrists and dermatologists. However, the statutes that formed the Spanish Group for Dermatology and Psychiatry were not formally approved until 1999. The management committee consisted of two dermatologists and a psychiatrist, Antonio Rodríguez-Pichardo, Francesc Grimalt and Joaquim Pujol [24]

Later, in Madrid, the Spanish Group for Dermatology and Psychiatry (SGDaP) was established under the Spanish Academy of Medical-Surgical Dermatology and Venereology and chaired by Antonio Rodríguez-Pichardo. Annual meetings were held in different parts of Spain, always during February. In February 2006, the meeting was chaired by Dr. Carmen Brufeau in Murcia.

In Tenerife, the meeting was chaired by Marta GarciaBustinduy in February of 2007. During this meeting, Maria José Tribó coordinated the Spanish group of Dermatology and Psychiatry (SGDaP).

The next meeting took place in 2008 in Zaragoza. It was organized by Lucia Tomás-Aragones \& Servando MarrónMoya. The next meeting was held in Valladolid in 2009 and was chaired by Alberto Miranda.

The last meeting was held in February in 2010 in Palma de Mallorca. It was chaired by Joan Escales-Taberner. Currently, the SGDaP is coordinated by Aurora GuerraTapia.

The rest of Europe also formed working groups that contributed to improving training in Psychodermatology. For example, in The Netherlands, psychodermatologic clinicians receive training in Psychotherapy, Psychology or Psychiatry. In Germany, the German Working Group on Psycho- 
Dermatology has developed training programs for basic psychosomatic dermatologists.

Most European countries have created their own working groups on Psychodermatology, such as the French Society for Dermatology and Psychosomatic, the Italian Society of Psychosomatic Dermatology, and the Dutch Society of Psychosomatic Dermatology, etc.

The German Working Group on Psychodermatology $(\mathrm{APD}=$ Arbeitskreis Psychosomatische Dermatologie) has developed an education program for dermatologists consisting of 80 hours of short-term medical education called psychosomatic basic knowledge. In 2005, they organized the $11^{\text {th }}$ International Congress of the ESDaP with Uwe Gieler from the University of Giessen.

The Italian Society of Psychosomatic Dermatology (SIDEP) was developed on November 4, 1995 (under the name of the Italian Group of Dermatology Psychosomatics GIDEP) in Venice on the occasion of the Residential Course of Psychosomatic Dermatology, held in Palazzo Giustiniani Lolin, home of the Fondazione Levi [24].

\section{HISTORY OF PSYCHODERMATOLOGY IN THE CILAD}

In October 2008, a group of dermatologists created a psychodermatology working group within the Ibero Latin College of Dermatology (CILAD). All dermatologists belonged to the CILAD. The working group was coordinated by Carmen Rodríguez-Cerdeira with the unconditional support of then-President of CILAD, Roberto Arenas Guzmán [28].

The founding members who proposed the creation of this group to the Board of the CILAD were as follows:

$\begin{array}{ll}\text { - } & \text { Carmen Rodríguez-Cerdeira (Spain) } \\ \text { - } & \text { Rafael Isa-Isa (Republica Dominicana) } \\ \text { - } & \text { Roberto Arenas-Guzmán (México) } \\ \text { - } & \text { Antonio Guzman (Paraguay) } \\ \text { - } & \text { Yolanda Ortiz (Mexico) } \\ \text { - } & \text { Marcela Gaete (Chile) } \\ \text { - } & \text { Mauricio Sandoval (Chile) } \\ \text { - } & \text { Eduardo José Restifo (Argentina) } \\ \text { - } & \text { Hector Murakami (Perú) } \\ \text { - } & \text { Eduardo Silva (Guatemala) }\end{array}$

In April 2009, the board of the CILAD announced the acceptance of this group, and the coordination of the group was assumed by Carmen Rodríguez-Cerdeira (Spain) and the Secretary General Rafael Isa-Isa (Dominican Republic).

The purpose of this chapter is to promote and cultivate existing relationships among the three disciplines, namely, Dermatology, Psychiatry and Psychology. It also seeks to publicize the results of the efforts made in the study of diseases covered by the three specialties, with the aim of improving the treatment of patients. It aims to contribute to meetings and publications of high academic value that will be disseminated among the scientific community. Finally, it aims to promote good relations between the different Dermatology and Psychiatry societies all over the world to attempt to unify therapeutic protocols [24].

Finally, the $30^{\text {th }}$ of September in 2011, Japan established the Japanese Society of Psychodermatology and held the 1st annual meeting in the Osaka, where the most prominent speakers as Eiichiro Ueda, Takashi Yamauchi, Yuko Higaki, Ritsuko Hosoya, Ryuzo Saito, among others, have been involved as it is reflected in the meeting web (http://www.jspd.org).

\section{FUTURE PROSPECTS}

This paper tries to highlight the importance of understanding psychosomatic problems and to develop a continuing medical education program (similar to that in other European countries). We hope that the dermatologists can appropriately counsel patients through better preparation and knowledge of the interaction between skin disorders and psychological problems.

We should try to establish ties that allow a working relationship between dermatologists, psychologists and psychiatrists. It is important for dermatologists to have basic knowledge about psychiatry. Doctors with less developed relation skills had more difficult consultations [29]. However, we cannot forget that in many cases, specialised psychiatric care is necessary (follow-up cases, psychotherapy, special prescription drugs) [30].

\section{CONCLUSION}

Until recently, when the link between the brain and skin was definitively proved in the field of psychoimmunology, the relationship between these two organs was largely unknown. It is likely that further psychodermatogical links will be revealed, and we will identify new relationships that will help us to better understand the association between Dermatology and Psychiatry.

Collaboration among dermatologists, psychiatrists and psychologists is evident throughout history, and the large number of scientific societies that have emerged in Europe and America reflect the continued growth of interdisciplinary research.

\section{REFERENCES:}

[1] Dantzer R, O'Connor JC, Freund GG, Johnson RW, Kelley KW. From inflammation to sickness and depression: when the immune system subjugates the brain. Nat Rev Neurosci 2008; 9: 46-56.

[2] Linthorst Homan MW, Spuls PI, de Korte J, Bos JD, Sprangers MA, van der Veen JP. The burden of vitiligo: patient characteristics associated with quality of life. J Am Acad Dermato 2009; 6: 41120.

[3] Linthorst Homan MW, de Korte J, Grootenhuis MA, Bos JD, Sprangers MA, van der Veen JP. Impact of childhood vitiligo on adult life. Br J Dermatol 2008; 159: 915-20

[4] Cossidente A, Sarti MG. History and fundamentals of psychosomatic dermatology. Clin Dermatol 1984; 2: 1-16.

[5] Poot F, Sampogna F, Onnis L. Basic knowledge in psychodermatology. J Eur Acad Dermatol Venereol 2007:2 1: 22734.

[6] Kimball AB, Jacobson C, Weiss S, Vreeland MG, Wu. The psychosocial burden of psoriasis. Am J Clin Dermatol 2005; 6: 383-92. 
[7] Koblenzer CS. Psychosomatic concepts in dermatology. A dermatologist-psychoanalyst's viewpoint. Arch Dermatol 1983; 119: 501-12.

[8] Schwab JJ. Psychosomatic medicine: it's past and present. Psychosomatics 1985; 26: 583-5, 588-9, 592-3.

[9] Kanareikin KF, Bakhur VT. Evolution of psychosomatic medicine. Klin Med (Mosk) 1989; 67: 16-21

[10] Koo JYM. Pham CT. Psychodermatology. Practical guidelines on pharmacotherapy. Arch Dermatol 1992; 128: 381-8.

[11] Agustín M, Cotteril J, Gieler U, Zschocke I. Skin and the psyche: closing the gap. Dermatol Psichosom 2000; 1: 4-7.

[12] Koblenzer CS, Koblenzer PJ, Tausk FA. What is psychocutaneous medicine? Cutis. 2008; 81: 487

[13] Tausk F, Elenkov I, Moynihan J. Psychoneuroimmunology. Dermatol Ther 2008; 21: 22-31.

[14] Cotterill JA. Dermatologic non desease. Dermatol Clin 1996; 14: 439-45.

[15] Panconesi E. Psychosomatic dermatology: past and future Int J Dermatol 2000: 39: 732-4.

[16] Musaph H. Psychodermatology. Psychother Pysychosom 1974; 24: 79-85.

[17] Escande JP. Institutional organization of a hospital dermatology service with a responsibility for psychosomatic care. Sem Hop 1984: 60: 916-9.

[18] Panconesi E. Psychosomatic factors in dermatology: special perspectives for application in clinical practice. Dermatol Clin 2005; 23: 629-33.
[19] Giovanni A, Nicoletta S. The Biopsychosocial Model Thirty Years Later. Psychother Psychosom 2008; 77: 1-2.

[20] Koblenzer CS. Psychocutaneous disease. Orlando: Grune \& Stratton, 1987.

[21] Griesemer RD. Emotionally triggered disease in a dermatology practice. Psychiatr Ann 1978; 8: 49-56.

[22] Le Moal M, Battin J, Bioulac B, et al. Neurosciences in Bordeaux Bull Acad Natl Med 2008; 192: 817-31.

[23] Gieler U, Niemeier V, Kupfer J, Harth W. Psychosomatic dermatology Hautarzt. 2008; 9: 415-32.

[24] Grimalt F, Cotterill J. Dermatología y Psiquiatría: historias clínicas comentadas. Madrid: Aulamedica, 2002

[25] Gieler U, Harth W. Psychodermatology. Hautzart 2008; 59: 287-8.

[26] Gieler U, Taube K. Comment on the continuing education article by R. Hoffmann and R. Happle "Alopecia areata". Position of the Psychosomatic Dermatology Professional Circle of German Dermatology Society. Hautarzt 1999; 50: 816-9.

[27] Koo J, Lebwohl A. Psychodermatology: The Mind and Skin Connection. Am Fam Physician 2001; 64: 1873-8

[28] Rodríguez-Cerdeira C. Fundamentos básicos en Psicodermatología. Tresctres: Santiago de Compostela (Spain), 2010.

[29] Poot F. Doctor-patient relations in dermatology: obligations and rights for a mutual satisfaction. J Eur Acad Dermatol Venereol 2009; 23: 1233-9

[30] Moffaert M. Psychodermatology: an overview. Psycother Psychosom 1992; 58:125-36.

(c) Rodríguez-Cerdeira et al.; Licensee Bentham Open.

This is an open access article licensed under the terms of the Creative Commons Attribution Non-Commercial License (http: //creativecommons.org/licenses/by$\mathrm{nc} / 3.0 /$ ) which permits unrestricted, non-commercial use, distribution and reproduction in any medium, provided the work is properly cited. 